Case Report

\title{
A Case of De Novo Anterior Condylar Dural Arteriovenous Fistula Long after Curative Transvenous Embolization of Contralateral Anterior Condylar Arteriovenous Fistula
}

\author{
Shinya Hagiwara, Takeshi Miyazaki, Masahiro Tsuji, Mizuki Kambara, \\ Tsutomu Yoshikane, Hidemasa Nagai, and Yasuhiko Akiyama \\ Department of Neurosurgery, Shimane University Faculty of Medicine, Shimane, Japan \\ Correspondence should be addressed to Shinya Hagiwara; hagiwara.shinya@outlook.jp
}

Received 11 August 2016; Accepted 29 September 2016

Academic Editor: Walter Zidek

Copyright ( 2016 Shinya Hagiwara et al. This is an open access article distributed under the Creative Commons Attribution License, which permits unrestricted use, distribution, and reproduction in any medium, provided the original work is properly cited.

We report on a 55-year-old man who developed a de novo DAVF in left ACC 5 years after curative transvenous embolization for DAVF in right ACC. Angiography revealed that the de novo lesion demonstrated more aggressive arteriovenous shunt flow than the initial lesion. Successful transvenous embolization was performed for also the second lesion. The authors describe the possible pathophysiological mechanisms and management strategies for this rare occurrence.

\section{Introduction}

Cranial dural arteriovenous fistula (DAVF) is abnormal arteriovenous shunts. It occurs anywhere in cranial sinus, commonly in cavernous and transverse sinus, and rarely in anterior condylar confluence (ACC). DAVF is treated with disconnection of the venous drainage system via endovascular intervention or surgical procedures [1]. It is rare that a second DAVF occurs in a remote area after resolution of other located first lesions [2-10]. Most of them develop in the region of downstream of the venous pathway where the first lesion located.

We report a very rare case of a de novo ACC DAVF in the contralateral ACC 3 years after unilateral ACC DAVF, treated by transvenous embolization.

\section{Case Presentation}

A 55-year-old man was admitted to our hospital with sudden pulsatile headache and pulse-synchronous tinnitus on the left occipital. Bruit was audible mainly on his left retroauricular area. He had past history of right ACC DAVF at 50 years of age (Figure 1). Its clinical manifestation was right-sided tinnitus and it was similar to the present symptoms. His right ACC
DAVF was treated with transvenous coil embolization in another hospital and its obliteration was angiographically confirmed. He had resolved clinical symptoms and stopped visiting the hospital 1 year after the treatment.

The diagnostic angiography in our hospital revealed a high flow DAVF close to left jugular foramen, and it was mainly fed by meningeal branch of bilateral ascending pharyngeal arteries. It was not only drained to left internal jugular vein and vertebral artery venous plexus, but also refluxed to contralateral transverse-sigmoid sinus and to cavernous sinus via inferior petrosal sinus. Those findings suggest this lesion to have high volume arteriovenous shunt flow (Figure 2(a)). The shunt point could not be identified by routine angiography because blood flow to the lesion was very high. The right ACC DAVF treated five years earlier was not depicted on the four vessels' study (Figure 2(b)). The shunt point was evaluated by angioarchitecture demonstrated by threedimensional angiography and by time-of-flight magnetic resonance angiography (MRA). Shunt point was identified on left ACC (Figure 3), and transvenous coil embolization was planned. Under general anesthesia, a 6 Fr guiding catheter was placed adjacent to the jugular bulb via right femoral vein, and a microcatheter was advanced into the left ACC. Superselective angiography of left ascending pharyngeal artery 


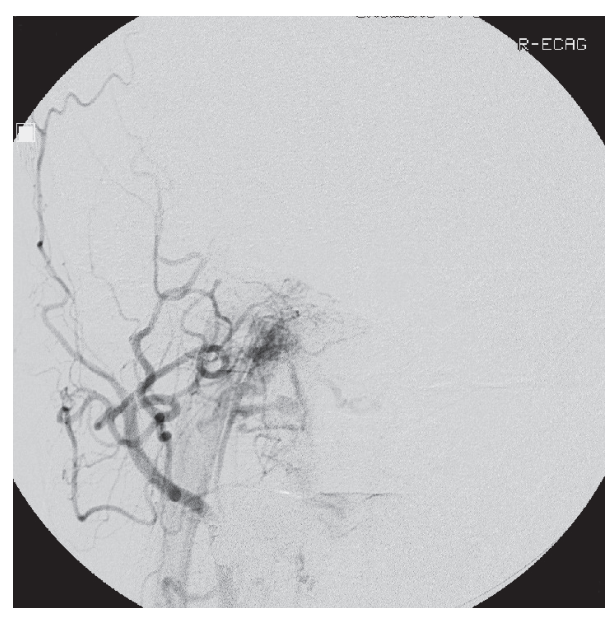

(a)

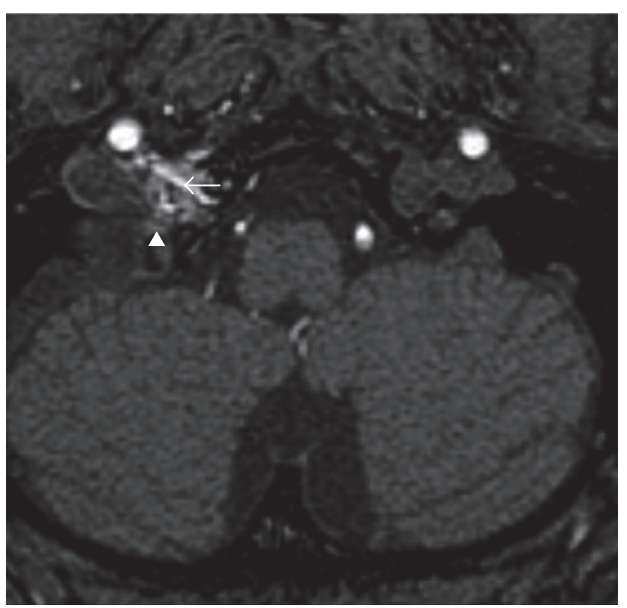

(b)

FIGURE 1: Right external carotid angiogram depicting dural arteriovenous fistula. It is fed by ascending pharyngeal artery and it drains to the vertebral venous plexus (a). Axial source image of time-of-flight MRA shows hyperintense thin vessel penetrating hypoglossal canal (arrow) and arterialized venous pouch of right anterior condylar confluence (arrowhead).

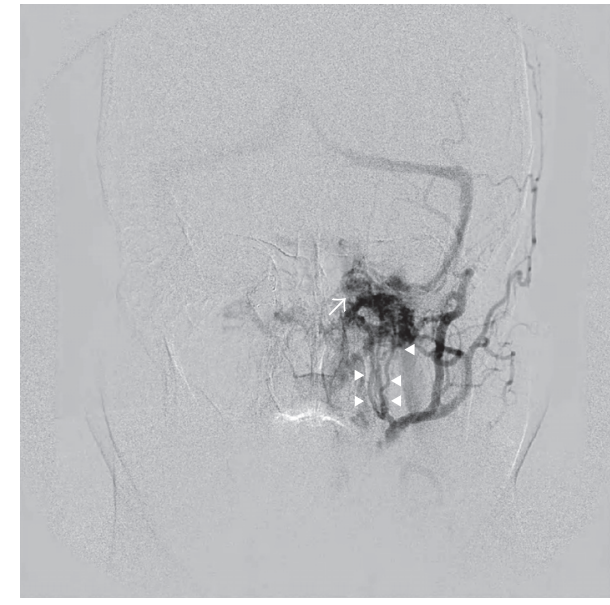

(a)

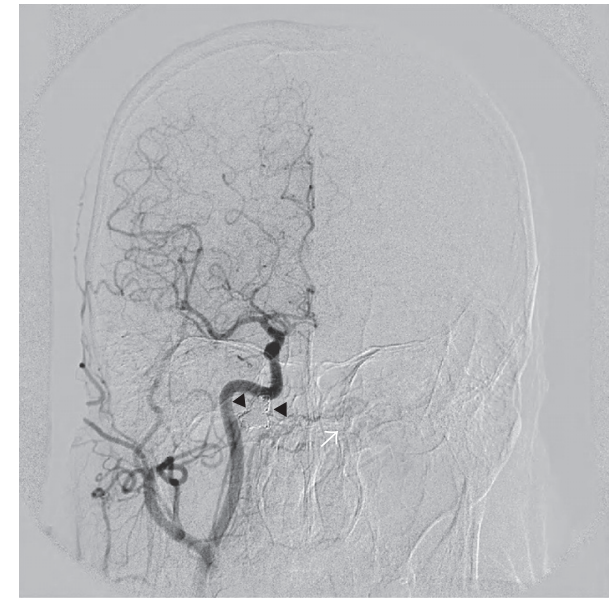

(b)

FIGURE 2: (a) Left external carotid angiogram demonstrates dural arteriovenous fistula around left jugular valve. Dural arteriovenous fistula is mainly fed by meningeal branches of the left ascending pharyngeal artery (arrowhead) and drained to left internal jugular vein, bilateral vertebral venous plexus through the left anterior condylar vein. Left cavernous sinus and transverse-sigmoid sinus are refluxed. Anterior condylar confluence is depicted as expanded venous pouch (arrow). (b) Right common carotid angiogram demonstrated obliteration of dural arteriovenous fistula in the right anterior condyle confluence. Coil mass inserted five years ago is depicted (arrowhead). Right ascending pharyngeal artery feeds dural arteriovenous fistula in the contralateral anterior condylar confluence.

confirmed that the microcatheter was accurately placed in ACC that is forming venous pouch, and then coil packing was carried out. Excess coil packing in hypoglossal canal results in hypoglossal nerve palsy; therefore, coil embolization was finished with angiography feeble of venous drainage. The patient's symptoms resolved just after the treatment. Followup angiography at one month after the embolization revealed complete obliteration of this de novo ACC DAVF (Figure 4), and $\mathrm{CT}$ after treatment demonstrates packing coil seated in right ACC to hypoglossal canal (treated 5 years ago) and in left ACC (Figure 5).

\section{Discussion}

A DAVF close to the jugular foramen has been referred to as various entities including the DAVF involving the marginal sinus, hypoglossal DAVF [11], DAVF of the anterior condylar vein within the hypoglossal canal [12], and jugular foramen DAVF [13]. The development of high resolution dimensional techniques for angiography has allowed identification of the shunt point of these DAVFs in small venous complex close to the hypoglossal canal. This complex is referred to as the ACC DAVF. ACC DAVF has its shunt near the petrous bone and patients feel severe tinnitus; however, definitive diagnosis 


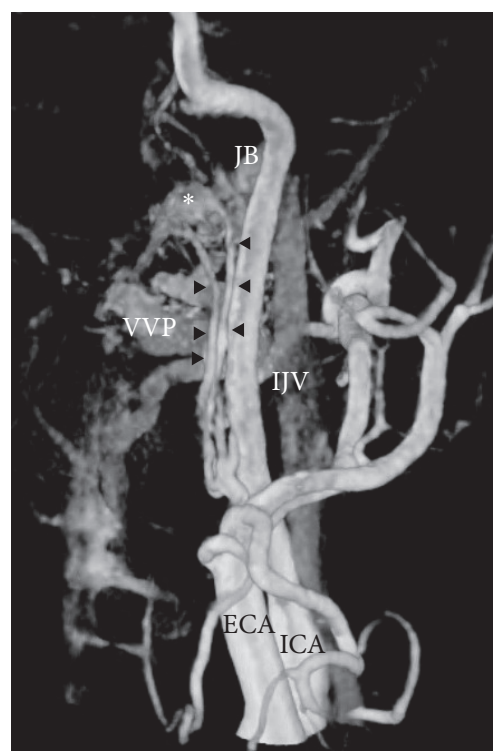

FIgure 3: Three-dimensional digital subtraction angiography revealed angioarchitecture surrounding the anterior condyle confluence dural arteriovenous fistula. Meningeal branches of ascending pharyngeal artery feed to anterior condyle confluence forming venous pouch (*). Jugular valve (JV), internal jugular vein (IJV), and vertebral artery venous plexus (VAVP) formed venous drainage.

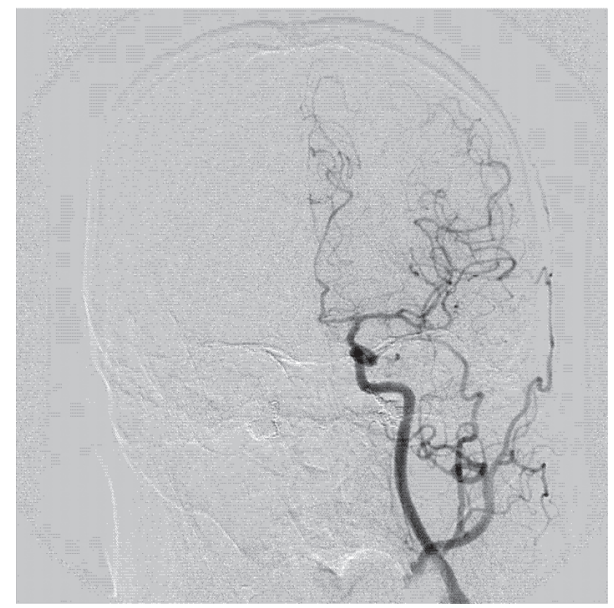

FIGURE 4: Left common carotid angiogram demonstrates complete obliteration of anterior condylar confluence dural arteriovenous fistula.

tends to be delayed. Pulsatile compression of the enlarged anterior condylar veins occasionally causes hypoglossal nerve palsy or involuntary movement of the tongue [14].

The present case is the first report of de novo ACC DAVF that occurred after curative treatment of contralateral ACC DAVF. DAVF is generally accepted to be an acquired vascular disease in adults. Although its exact pathogenesis is unclear, it is considered that venous hypertension due to sinus thrombosis enlarges the physiological minute arteriovenous connection which normally presents within the dura matter and results in occurrence of abnormal dural arteriovenous shunt

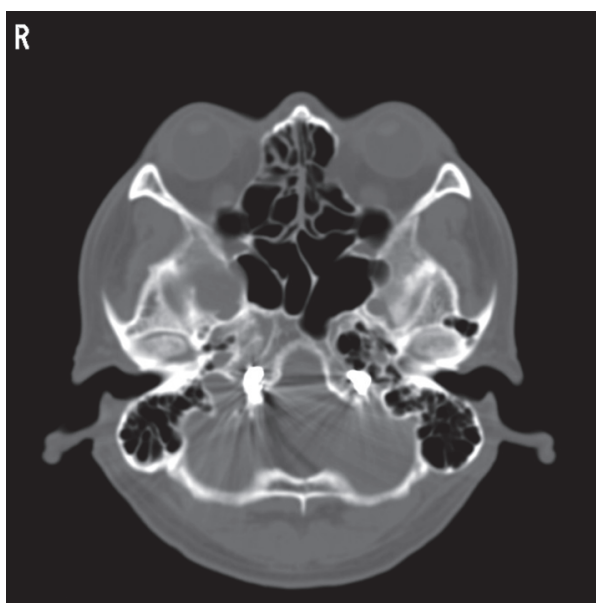

FIGURE 5: CT after treatment demonstrates packing coil seated in right ACC to hypoglossal canal (treated 5 years ago) and in left ACC.

[15]. Animal model and surgical specimens also postulate that sinus thrombosis is the key to develop DAVF $[16,17]$. In some cases, multiple lesions are simultaneously found at the time of diagnosis and this is generally called multiple DAVFs. Recent studies revealed that these synchronous multiple lesions are found in 7 8\% of intracranial DAVFs $[3,18]$. On the other hand, second DAVF development in another sinus after resolution of the first lesion is rare. The cases with such second DAVF can be called metachronous multiple DAVFs. To our knowledge, thirteen cases have been reported [2-10]. Interestingly, most of these second lesions in metachronous multiple DAVF, twelve among the thirteen lesions, had developed downstream of the same venous pathway where the first lesion located. This phenomenon might be also explained by above described theory that venous hypertension in morbid sinus derives DAVF occurrence. The second de novo lesion developed within one year after the obliteration of the first lesion (range from 4 to 92 months). The second DAVF on the ipsilateral side may explain development from persisting venous hypertension after the endovascular shunt point disconnection. There are two cases of reported incidence of de novo DAVF developed on the contralateral side of the initial location including our case. Kurl et al. reported a case of right transverse-sigmoid sinus DAVF that developed twenty-three months after the transarterial embolization with N-butyl cyanoacrylate (NBCA) [6]. In this case, they did not detect signs of thrombosis or deformation on sinuses. Likewise, we did not detect thrombosis or stenosis in any sinus in our case. Although only few cases of de novo lesion on the contralateral side are reported, the interval between the first lesion and the second lesion appears to be longer than ipsilateral occurrence. Not only venous hypertension, but also unknown genetic factor may associate with developing the DAVFs.

Ha et al. studied clinical and angiographic characteristics of multiple DAVF. They found that both synchronous and metachronous multiple DAVFs have aggressive angiographic and clinical symptoms, and they concluded that aggressive management is necessary for these cases with multiple lesions 
[3]. The present case also demonstrates larger volume of shunt flow and higher degree venous reflux than initial lesion. Secondly developed DAVF may need the aggressive treatment even wherever it occurred. It will be important to find out the second lesion to avoid the poor clinical prognosis of the patient. Recently, MRI including time-resolved MRA imaging is recommend as one of the useful diagnostic tools [19]; however, it is yet unclear what type of patient needs longer follow-up and for how long should the patients be observed after the treatment of DAVF. These still remain as clinical research subject to clarify the pathophysiology of cranial DAVF.

\section{Conclusion}

We reported a rare case of metachronous bilateral ACC DAVF. Although second DAVF development is rare, it may manifest aggressive angiographic and clinical symptoms. Accurate diagnosis in early stage is important, and aggressive management will be mandatory.

\section{Abbreviations}

DAVF: Dural arteriovenous fistula

ACC: Anterior condylar confluence

MRA: Magnetic resonance angiography

NBCA: N-Butyl cyanoacrylate.

\section{Competing Interests}

The authors have no competing interests regarding this article. All authors who are members of the Japan Neurosurgical Society (JNS) have registered online Self-Reported COI Disclosure Statement Forms through the website for JNS members.

\section{References}

[1] H. Kiyosue, Y. Hori, M. Okahara et al., "Treatment of intracranial dural arteriovenous fistulas: current strategies based on location and hemodynamics, and alternative techniques of transcatheter embolization," Radiographics, vol. 24, no. 6, pp. 1637-1653, 2004.

[2] R. Gupta, M. Horowitz, A. Tayal, and T. Jovin, "De novo development of a remote arteriovenous fistula following transarterial embolization of a carotid cavernous fistula: case report and review of the literature," American Journal of Neuroradiology, vol. 26, no. 10, pp. 2587-2590, 2005.

[3] S. Y. Ha, Y. S. Kwon, B. M. Kim, D. I. Kim, and D. J. Kim, "Clinical and angiographic characteristics of multiple dural arteriovenous shunts," American Journal of Neuroradiology, vol. 33, no. 9, pp. 1691-1695, 2012.

[4] H. Kiyosue, S. Tanoue, M. Okahara, M. Yamashita, H. Nagatomi, and H. Mori, "Recurrence of dural arteriovenous fistula in another location after selective transvenous coil embolization: report of two cases," American Journal of Neuroradiology, vol. 23, no. 4, pp. 689-692, 2002.

[5] Y. Kubota, T. Ueda, Y. Kaku, and N. Sakai, "Development of a dural arteriovenous fistula around the jugular valve after transvenous embolization of cavernous dural arteriovenous fistula," Surgical Neurology, vol. 51, no. 2, pp. 174-176, 1999.

[6] S. Kurl, R. Vanninen, T. Saari, and J. Hernesniemi, "Development of right transverse sinus dural arteriovenous malformation after embolisation of a similar lesion on the left," Neuroradiology, vol. 38, no. 4, pp. 386-388, 1996.

[7] N. Kuwayama, A. Takaku, M. Nishijima, S. Endo, and M. Hirao, "Multiple dural arteriovenous malformations. Report of two cases," Journal of Neurosurgery, vol. 71, no. 6, pp. 932-934, 1989.

[8] T. Makiuchi, K. Takasaki, M. Yamagami et al., "A case of sigmoid sinus dural arteriovenous fistula after treated cavernous dural arteriovenous fistula," Interventional Neuroradiology, vol. 4, no. 1, pp. 219-222, 1998.

[9] H. Nakagawa, S. Kubo, Y. Nakajima, S. Izumoto, and T. Fujita, "Shifting of dural arteriovenous malformation from the cavernous sinus to the sigmoid sinus to the transverse sinus after transvenous embolization: a case of left spontaneous carotidcavernous sinus fistula," Surgical Neurology, vol. 37, no. 1, pp. 30-38, 1992.

[10] K. Yamashita, W. Taki, I. Nakahara, S. Nishi, A. Sadao, and H. Kikuchi, "Development of sigmoid dural arteriovenous fistula after transvenous embolization of cavernous dural arteriovenous fistula," American Journal of Neuroradiology, vol. 14, pp. 1106-1108, 1993.

[11] M. Okahara, H. Kiyosue, S. Tanoue et al., "Selective transvenous embolization of dural arteriovenous fistulas involving the hypoglossal canal," Interventional Neuroradiology, vol. 13, no. 1, pp. 59-66, 2007.

[12] R. Ernst, R. Bulas, T. Tomsick, H. Van Loveren, and K. A. Aziz, "Three cases of dural arteriovenous fistula of the anterior condylar vein within the hypoglossal canal," American Journal of Neuroradiology, vol. 20, no. 10, pp. 2016-2020, 1999.

[13] N. Kuwayama, T. Akai, Y. Horie, M. Nishijima, S. Endo, and A. Takaku, "Dural arteriovenous fistulae involving the transversesigmoid sinus and foramen magnum," Surgical Neurology, vol. 41, no. 5, pp. 389-395, 1994.

[14] O. Combarros, A. Alvarez De Arcaya, and J. Berciano, "Isolated unilateral hypoglossal nerve palsy: nine cases," Journal of Neurology, vol. 245, no. 2, pp. 98-100, 1998.

[15] M. T. Lawton, R. Jacobowitz, and R. F. Spetzler, "Redefined role of angiogenesis in the pathogenesis of dural arteriovenous malformations," Journal of Neurosurgery, vol. 87, no. 2, pp. 267-274, 1997.

[16] T. Terada, R. T. Higashida, V. V. Halbach et al., "Development of acquired arteriovenous fistulas in rats due to venous hypertension," Journal of Neurosurgery, vol. 80, no. 5, pp. 884-889, 1994.

[17] R. Uranishi, H. Nakase, and T. Sakaki, "Expression of angiogenic growth factors in dural arteriovenous fistula," Journal of Neurosurgery, vol. 91, no. 5, pp. 781-786, 1999.

[18] J. M. C. van Dijk, K. G. TerBrugge, R. A. Willinsky, and M. C. Wallace, "Multiplicity of dural arteriovenous fistulas," Journal of Neurosurgery, vol. 96, no. 1, pp. 76-78, 2002.

[19] S. Meckel, M. Maier, D. San Millan Ruiz et al., "MR angiography of dural arteriovenous fistulas: diagnosis and follow-up after treatment using a time-resolved 3D contrast-enhanced technique," American Journal of Neuroradiology, vol. 28, no. 5, pp. 877-884, 2007. 


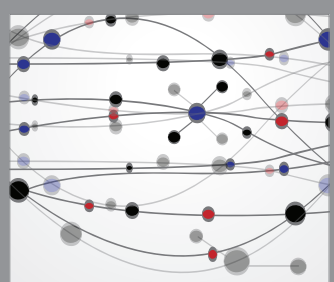

The Scientific World Journal
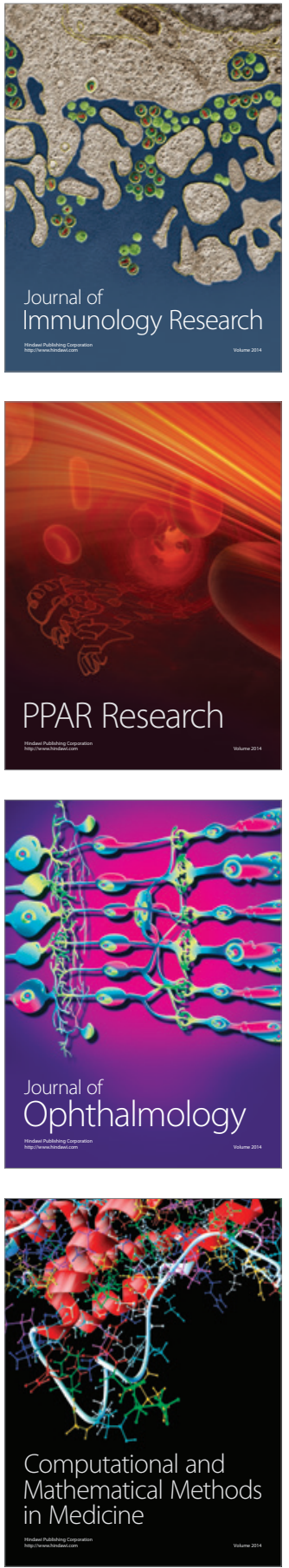

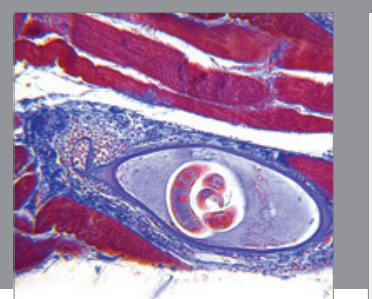

Gastroenterology Research and Practice

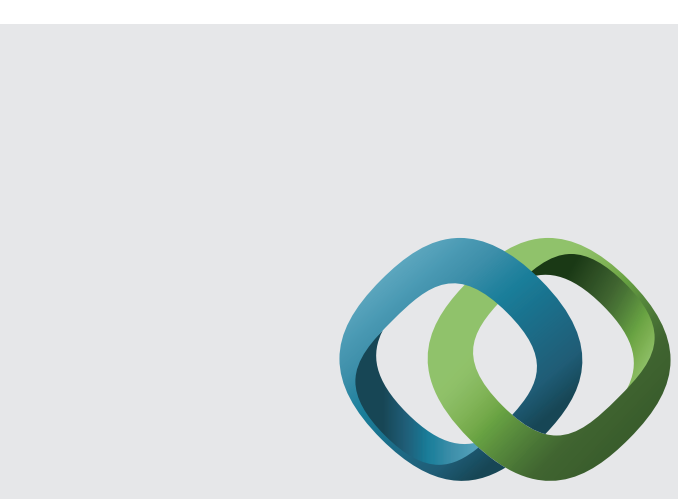

\section{Hindawi}

Submit your manuscripts at

http://www.hindawi.com
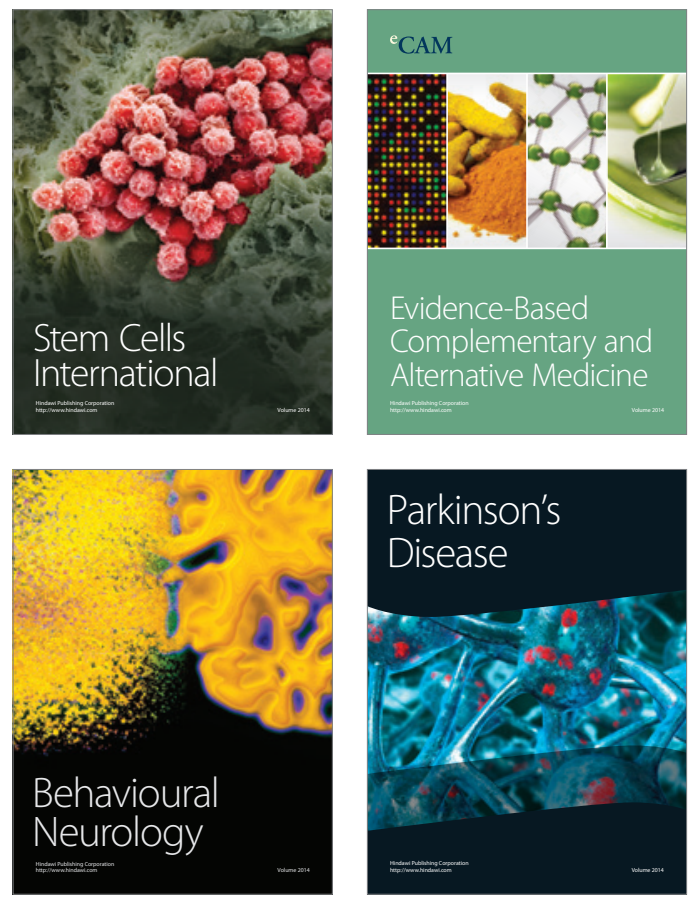
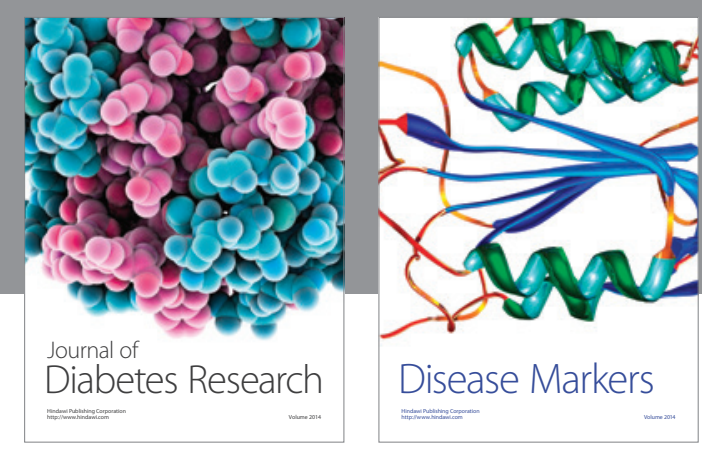

Disease Markers
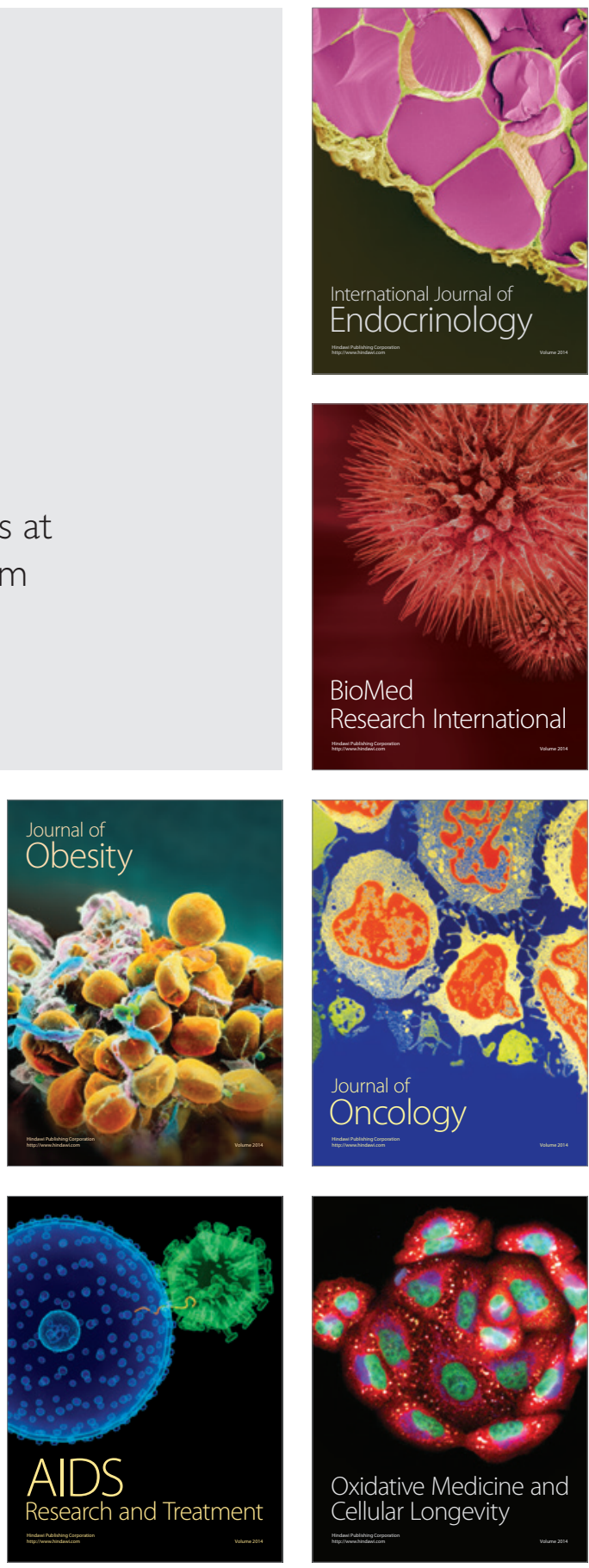